\title{
O poder pastoral em Gregório I: um mapeamento teórico
}

\author{
Pastoral power in Gregory I: a theoretical mapping
}

\begin{abstract}
Rodrigo Fernandes Vicente ${ }^{1}$
${ }^{1}$ Mestrando no Programa de Pós-Graduação em História da Universidade Federal de São Paulo (PPGH/UNIFESP); é graduado em História pela mesma universidade. Estuda a transformação das relações de poder na península Itálica dos séculos VI e VII, e as convergências e divergências entre bizantinos e ocidentais a partir da perspectiva do papado de Gregório I (590 - 604 EC). Está vinculado ao Laboratório de Estudos Medievais (LEME/UNIFESP) e ao Laboratório de Estudos Bizantinos e Mediterrânicos (LAEMEB/LEME-UNIFESP). Orientador: Prof. Dr. Fabiano Fernandes. Contato: rodrigofevicente@gmail.com/ r.vicente@unifep.br.
\end{abstract}

Recebido em 30 de março de 2021; Aceito em 9 de julho de 2021.

DOI: $10.12957 /$ nearco.2021.58791

\section{Resumo}

Parte de um trabalho monográfico, o presente artigo se dispõe em analisar a forma como que o papa Gregório I - ou Magno - (pontificado 590 - 604) concebeu o poder pastoral através de sua Regula Pastoralis. Elaborada logo após a ascensão de Gregório ao trono de Pedro, a Regula é abordada no sentido de mapear a dinâmica de poder encarada por Gregório e os problemas enfrentados durante o seu pontificado.

Palavras-chave: Gregório I; História da Igreja; poder pastoral.

\begin{abstract}
As a part of an undergraduate thesis, this article analyzes the way in which Pope Gregory I - or the Great - (pontificate 590-604) conceived the pastoral power through his Regula Pastoralis. Elaborated shortly after Gregory's ascension to the throne of Peter, the Regula is approached in the sense of mapping the power dynamics faced by Gregory and the problems faced during his pontificate.
\end{abstract}

Keywords: Gregory I; Church History; pastoral power.

Há algum tempo em que os historiadores debatem acerca da transição da antiguidade para o feudalismo. Nomes como Edward Gibbon, Marc Bloch, Moses Finley, Perry Anderson - e até mesmo sociólogos como Max Weber -, se debruçaram sobre essa época que, de tão distante e com tão poucas fontes, já foi dada como uma "Idade das Trevas". Mas até hoje essa questão se faz candente. Desde o início dos anos de 1970 com a publicação de The World of Late Antiquity (1971), Peter Brown colocou uma nova 
luz sobre o tema propondo uma continuidade do mundo antigo - desde meados do século III até o alvorecer do mundo carolíngio, no século VIII - agora reformulado sob matrizes cristãs. A tese de Brown causou um grande impacto no meio acadêmico ao ponto de que, após quase cinco décadas, ainda vermos os termos "antiguidade tardia" nos trabalhos acadêmicos sobre o período. Declinando do conceito de Brown, neste texto procuro usar outras balizes teóricas, é evidente que temos uma herança da antiguidade, principalmente se estamos tratando da cidade de Roma, mas o que interessa aqui é: como Roma desenvolveu sua influência sobre o mundo mediterrânico além de seu passado imperial glorioso? (MASKARINEC, 2018, p. 11) Fato é que tratamos aqui de uma cidade que apenas era uma sombra daquilo que fora um dia, e que tínhamos somente uma instituição que referendava a importância da cidade naquele momento: a Igreja.

Aqui, ao nos pautarmos sob o prisma do materialismo histórico-dialético, vemos que os conflitos emergem como expressão do funcionamento da sociedade e das contradições que nela existem (BASTOS, 2010, p. 77), e que justamente nesse período de transição da antiguidade da Idade Média, nós temos uma crise econômica e espiritual que atinge fortemente o Império Romano o fazendo ceder em partes, e se remodelar em outras. Para isso, novas narrativas de poder surgem, e é nisso que vamos nos ater.

A Roma de Gregório I era uma cidade decadente; destruída por conta de séculos de guerras e saques, e constantemente sofria com pestes. O rio Tibre, quando de fato era um dos principais rios propiciava a agricultura no Lácio, inundava e destruía tudo aquilo que havia de subsistência para a pobre população - como fora em meados de 590. Gregório Magno, em suas Homilias sobre Ezequiel, pregadas em uma cidade sitiada pelos lombardos (no inverno de 592/93) trona-se um grito abafado de uma Roma que clama pela ajuda do poder imperial bizantino enquanto navegava "por um mar de espadas lombardas" - e tudo aquilo soava para Gregório como claros sinais das trombetas do apocalipse (DEMACOPOULOS, 2015, p. 92). A região do Lácio, em meados do século VI, de fato sofreu com as campanhas militares contra os Godos enviadas por Justiniano e comandadas por Belisário naquilo que ficou conhecido como a Guerra Gótica; após conquistarem a África setentrional do Vândalos, Belisário varreu o poder 
gótico da Itália trazendo o Cidade Eterna de volta para o seio da romanitas. Mas Gregório nos apresenta um mundo em desolação. Alguns historiadores como Bronwen Neil (2013, p. 3-4) afirmam que Gregório se utiliza constantemente de hipérboles como uma forma de sensibilizar o poder imperial para a sua situação. De fato, não podemos nos esquecer que o século VI na Itália foi particularmente caótico, com diversas guerras, invasões e pestes. Seu próprio predecessor, Pelágio II, morreu de peste em 589. Com um mundo agonizante, Gregório verá na Igreja como um sustentáculo daquilo que restava de ordem no mundo italiano de sua época, não à toa, todas as suas políticas se definem como uma tentativa de organizar o mundo e o seu entorno, com a Igreja servindo de alento para uma população sofrida, e a sua liderança servindo de rector para uma sociedade em crise. Essas reflexões de Gregório serviram de norte para a análise da Regula pastoralis, um manual de conduta elaborado no início de seu pontificado (em meados de 590/591) e representa o cerne daquilo que Gregório entende como rector e do papel do episcopado (ou do governador civil) perante a sociedade.

O Mediterrâneo de Gregório era ainda um mundo conectado. O mare nostrum dos romanos ainda continuava com a suas rotas comercias de circulação de bens e pessoas ativas a despeito da deposição de Rômulo Augusto pelos Ostrogodos em 476, porém, o centro deste mundo era outro (BOY, 2019, p. 146). Com a cidade de Roma empobrecida e sem muita influência política, a grande cidade que regia o domínio das águas Mediterrânicas era Constantinopla - a atual capital imperial. Gregório, um grande intelectual para sua época, é dado como um dos grandes doutores da Igreja e reconhecido como um dos grandes nomes da patrística ocidental. Gregório foi um dos nomes centrais em sua época pois se encontrava no encontro de várias encruzilhadas: entre um mundo latino e grego; entre um mundo romano e bárbaro. Isto é, estudando Gregório Magno nós temos um leque aberto das conexões possíveis da alta Idade Média, nós podemos tanto relacionarmos as ligações entre a península Itálica e o mundo germânico (com a Missão Gregoriana aos anglo-saxões levada a cabo pelo monge Agostinho - que posteriormente veio a se tornar o primeiro bispo da Cantuária, - por exemplo), ou relacionarmos a posição de Roma no tabuleiro do Império Bizantino da época e suas relações com as demais Sés do mediterrâneo (Constantinopla, Alexandria, 
Antioquia, entre outras). Temos uma série de possibilidades analisando as posições políticas e teológicas de Gregório. É prudente salientar que, a partir do momento em que o historiador busca utilizar debruçar-se na análise das formações econômicas précapitalistas com base no materialismo histórico-dialético as relações entre público e privado, Estado e Igreja, são muito mais obscuras do que em outros recortes. Até mesmo alguns historiadores renomados como Henri Pirenne em seu monumental Maomé e Carlos Magno derrapa nesses quesitos ao estabelecer o Reino Franco como um Estado laico. Se o historiador for rigoroso, até mesmo a noção de Estado é problemática utilizar para os recortes delimitados no pré-capitalismo. Quando Karl Marx (2011) lança os olhos para a sociedade romana clássica se depara com o latifudium que em certa medida sobrevive até a época de Gregório Magno que inclusive será fundamental para um momento de penúria abastecer a cidade de Roma onde Gregório utiliza terras de sua própria família para o abastecimento da urbi.

Nascido, aproximadamente, no ano de 540 - no seio de uma das poucas famílias senatoriais remanescentes em Roma e que detinha antigas relações com a Igreja -, Gregório obteve uma educação de bom nível nos moldes do trívium - sendo versado em gramática, retórica, literatura e com bons conhecimentos em direito. Tal como Santo Agostinho (354 - 430), bispo de Hipona, descreveu em suas Confissões, Gregório demonstrou ter pouco (ou nenhum) domínio da língua grega. O historiador bizantinista norte-americano Andrew Ekonomou (2007, p. 6) levanta a hipótese de que, sendo eles grandes teólogos cristãos, cada um em sua época, certamente detinham algum domínio do grego dada a grande proeminência dos autores orientais no cristianismo da época. Agostinho, até mesmo por conta da biografia, talvez realmente tivesse pouco domínio do grego, mas no caso de Gregório certamente algum domínio da língua grega ele teve, apesar de seu conhecimento a respeito de literatura e mitologia helênica se deu, sobretudo, através de traduções latinas.

Ekonomou afirma que Gregório tinha um profundo sentimento de pertencimento à Roma e tinha em Agostinho uma das suas principais referências teológicas. Logo após as Guerras Góticas houve um grande fluxo de oficiais imperiais do Oriente em direção a Roma e a Ravena. Com o Papa Virgílio clamando por uma "unidade 
do mundo romano [Romanitas]", logo após a controvérsia dos Três Capítulos, diversas obras da patrologia Grega foram traduzidas para o latim, contribuindo assim para que Gregório entrasse em contato com pensadores gregos como o seu homônimo Gregório Nazianzeno que foi uma das grandes bases para a sua produção teológica. Num momento em que a educação clássica quase se extinguiu em Roma, os estudiosos da cidade pouco tinham acesso a textos clássicos devido aos constantes assaltos à Cidade Eterna. No momento posterior as Guerras Góticas, houve tentativas de revitalizar a cidade por parte de Justiniano - vale lembrar que Roma não tinha (e nunca teve) um sistema educacional mantido pelo poder imperial na cidade. Com o passar do tempo o entusiasmo em revitalizar Roma foi cessando e, por fim, Roma foi administrada como uma província qualquer (EKONOMOU, 2007, pp. 6-8). Fato é que a educação recebida por Gregório lhe parece bastante favorável a quem se destina a administração da coisa pública. Subordinada ao Exarcado de Ravena ${ }^{263}$ dentro da organização imperial bizantina; Gregório aos 33 anos, tal como ocorrera com seu pai, acende ao cargo de prefeito de Roma, topo da administração civil da cidade. Gregório exerceu a prefeitura entre 572 e 575, onde sua atividade civil coincide com a primeira fase de expansão dos Lombardos ao norte da península Itálica. Após isso, retirou-se no Mosteiro de Santo André numa antiga villa de propriedade de sua família nos arredores da cidade (onde atualmente fica a Igreja de San Gregorio al Celio) dando início a sua trajetória religiosa e de profunda contemplação e ascetismo. Em sua vida monástica Gregório procurava seguir os preceitos de Atanásio de Alexandria e de Basílio, o Grande, em que tentava adaptar o modo de vida ascético dos Padres do Deserto para o meio urbano. Ekonomou $(2007$, p. 7) argumenta que, se os gregos não foram tão influentes para a educação cívica de Gregório, o seu modo de vida religioso era amplamente influenciado pela patrística oriental. Apesar disso, um dos poucos autores gregos que Gregório cita nominalmente é o de Gregório Nazianzeno, seu homônimo, que teve uma biografia similar a sua ao

\footnotetext{
263 O Exarcado de Ravena era a divisão administrativa do Império Bizantino que governava a Itália; Foi formado logo após a invasão lombarda, substituindo a antiga prefeitura, e tinha em seus exarcas quase

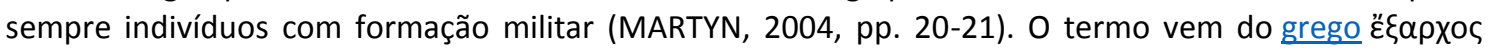
[eksárkhos], "chefe, pontífice máximo, comandante militar", Gregório chegou a se corresponder com todos os exarcas que ocuparam o cargo durante o seu pontificado.
} 
iniciar a vida religiosa no ascetismo para posteriormente exercer o cargo de patriarca de Constantinopla. É provável que a obra de Nazianzeno tenha sido lida por Gregório ainda em Roma na efervescência grega na cidade posterior a Reconquista de Justiniano, mas o próprio Andrew Ekonomou não nos dá certeza desta informação. Após a experiência como administrador civil, Gregório foi ordenado diácono pelo papa Pelágio II, e enviado para o cargo de apocrisário apostólico no intuito de defender os interesses da Sé de Roma junto a corte imperial em Constantinopla em 579. Pelágio II valeu-se da experiência de Gregório como administrador na prefeitura de Roma para o cargo e Demacopoulos (2015) destaca que este período de Gregório junto a autoridade imperial foi de fundamental importância para compreendermos a sua atuação como papa na posteridade.

Com a morte de Pelágio II em 589 - causada pela peste, que fora uma dentre as inúmeras tragédias que atingiu Roma nos momentos finais do século VI - Gregório logo foi aclamado Papa. Com a inexistência do conclave, os Papa (tais como as canonizações) eram eleitos na base da aclamação popular. Gregório retirou-se da vida monástica em que havia regressado desde o seu retorno de Constantinopla em 585, mas não se sentiu preparado, inclusive para fora de Roma partiu. Ao aceitar o bispado de Pedro, Gregório logo redigiu a sua Regula pastoralis em 591. Em um momento em que o poder secular havia sido reduzido à insignificância em Roma, com o senado reduzido ao pó posteriormente as Guerras Góticas, e com grande parte da elite romana se refugiando em suas propriedades rurais na Sicília ou em busca de um resto de prestígio junta a corte de Constantinopla, a Igreja se tornou a única instituição sólida em Roma. A intenção de Gregório com a Regra coloca-se clara: disciplinar o episcopado. De fato, como Claudia Rapp (2005) nos mostra, nós temos aqui um novo tipo de liderança surgindo, que neste caso é a liderança levada a cabo pelos bispos.

O Cisma dos Três Capítulos, cuja as origens remontam o Concílio da Calcedônia em meados de 451 e que acabou se intensificando no Segundo Concílio de Constantinopla em 553, provocou fraturas na península Itália principalmente nas Sés ao norte da península. Como Robert Markus (1997, pp. 125-7) nos lembra, este é apenas mais uma das dramáticas querelas cristológicas que casou cismas tais como as Igrejas 
do Egito e da Síria que enfraqueceram a unidade imperial provocando uma fratura na unidade da romanitas e propiciando essas regiões a invasões. Não é via de regra e nem uma mera ação e reação que o norte da Itália se tornou propício para as invasões lombardas unicamente por conta do cisma, a expansão dos ávaros advindos da Ásia central empurrou os lombardos obrigando-os a atravessares os alpes e assim encontrarem a região milanesa completamente desprotegida com o império pro vezes preferindo manter as tropas no oriente na luta contra os persas sassânidas do que deixálos na Itália e proteger o norte. Como mencionado, a época de Gregório é um momento de fragilização econômica, social e política de Roma, cuja a proteção não era uma das maiores prioridades para o Império. Os perigos de um novo ataque lombardo constantemente prejudicavam a comunicação de Roma com Ravena (exarcado e principal posto da administração imperial na província) ou com Constantinopla. Com o envio de alimentos para Roma sendo escasso a cidade necessitava constantemente da caridade da Igreja. Gregório utilizou inclusive terras de sua família na Sicília - que posteriormente foram cedidas a Igreja - Gregório organizava carregamentos de grãos que eram transportados em embarcações da ilha até Roma, onde posteriormente eram distribuídos a população. A distribuição de grãos foi mantida após a morte de Gregório Magno em 604 - dado que suas propriedades foram transferidas aos bens da Igreja -, porém tais suprimentos não eram mais disponibilizados de maneira gratuita a partir do pontificado de Bonifácio III (DEMACOPOULOS, 2015, p. 104).

Através de uma cuidadosa análise das cartas de Gregório nós podemos observar como ele se utilizava da sua retórica com o Imperador Maurício para obter ganhos políticos, pastorais e teológicos subvertendo a lógica greco-romana de, como subordinado, orientar o imperador em suas responsabilidades. Gregório, numa linguagem respeitosa e suave, argumenta com Maurício que tem muito mais legitimidade para gerir questões que envolve a Igreja pois ele mesmo se considera como um embaixador de Deus. Isto é, naquilo que se dizia respeito das questões temporais, o imperador era a autoridade legitima; porém, em questões relacionadas a Igreja e tudo naquilo que se dizia a respeito de questões teológicas e missionárias (isto é, em tudo aquilo que dizia a respeito da christianitas) Gregório se considerava muito mais legítimo 
que o imperador (DEMACOPOULOS, 2015, p. 89). Em uma das recomendações que Gregório envia ao imperador como forma de resistência aos bárbaros consistia, sobretudo, numa conversão deste povo do paganismo e do arianismo ao catolicismo; fora isso também eram salientadas melhorias nas devesas das cidades e a resolução da cisma dos três capítulos. A despeito de tudo isso, desde o início do seu pontificado Gregório dá indícios de envio de missões evangelizadoras aos Lombardos. Tentativas de conversão através da Rainha Teodolinda, esposa de Agilolfo. (DEMACOPOULOS, 2015, p. 118). É aqui importante salientarmos que a política de proteção de Roma de Gregório foi bem-sucedida pois, foi formada um equilíbrio de poderes dentro da península em que, por mais que os duques lombardos conspirassem em atacar Roma, tal atitude nunca se mostrou bem-sucedida. Basta analisarmos que o Exarcado de Ravenna - polo do poder Imperial na península - preferiu defender a rota dentre Roma e Ravenna do que a cidade em si. As tropas em imperiais em Roma se encontravam mal pagas e mal treinadas e, além disso, uma praga atingiu a cidade em 592. A trégua entre romanos e lombardos foi costurada graças a negociação de paz entre Gregório e o rei Agilolfo. Em 595 numa das viajem em que o rei bárbaro fora a Roma encontrar Gregório, o papa acabou por convencendo os lombardos que a Igreja e o Império eram instituições distintas. Ao contrário do rei godo Teodorico, que incentivou as artes, respeitou o Senado, e inclusive patrocinou intelectuais como Boécio, os lombardos destruíam todo e qualquer resquício de romanidade por onde passavam (ANDERSON, 2013, p. 139). Isso posto, Gregório observou a necessidade de uma re-romanização do norte da península.

A questão aqui torna-se clara, Gregório, estando numa encruzilhada entre poderes e civilizações - o mundo grego versus o mundo latino, a civilização romana versus os bárbaros - se viu no meio de numa disputa pela hegemonia do poder. Gregório antes de tudo se mostrava um programático apesar dele falar "a língua do Império" em seus escritos, e de exaltar a figura do Imperador, inclusive entre os bárbaros, como o modelo de monarca e de ortodoxia cristã, a sua maneira de agir por vezes se mostrava avessa daquilo que pregava (MARKUS, 1997, p. 84). Desde os primeiros séculos da cristandade o poder civil tinha em torno de si um caráter sagrado, todo Imperador era um enviado de Deus na terra, e - por mais que o governante seja um déspota - sua 
população deveria abençoá-lo e resignar-se, pois, se ele lá estava era porque Deus assim queria. Nas Sagradas Escrituras encontramos Paulo de Tarso afirmando categoricamente em sua epístola aos romanos que "cada um se submeta às autoridades constituídas, pois não há autoridade que não venha de Deus, e as que existem foram estabelecidas por Deus" (Rm, 13:1). Ora, a teologia cristã sempre demostrou grandes dificuldades em lidar com o poder secular em sua história, até porque, como líder com o poder terreno se Cristo afirmou que seu Reino não é deste mundo? (Jo, 18:36). Os primeiros padres da Igreja debruçaram-se enormemente dentro deste debate que, infelizmente, não vamos conseguir da conta neste trabalho. Como Eusébio de Cesareia defendeu, o Imperador era diretamente responsável por estabelecer a Pax Christiana e a Pax Romana, até porque a noção monoteísta em centrar toda a fonte de poder em um único Imperador tornou a doutrina cristã bastante palatável para o Império.

Uma análise crítica que podemos fazer da Regula pastoralis é dela enquanto um projeto de poder. Ao Gregório estabelecer preceitos morais do seu espiscopado, além de instruí-los como admoestar diferentes tipos de pessoas: "coléricos ou mansos", "ricos ou pobres", Gregório aqui nos apresenta as bases da expansão da Sé de Roma entre os germanos, isto é, num momento em que Roma estava sendo posta de maneira cada vez mais marginal dentro do mundo Imperial, Gregório olhou para os novos Reinos germânicos que se formavam no seu entrono como um meio de expansão, influência e hegemonia. Um dos exemplares da Regula pastoralis foi enviada a João, bispo de Ravenna, e amigo de Gregório. É certo notar que por um longo tempo Ravenna foi um problema para Roma por ser a cede do poder civil na península desde o final do Império Romano do Ocidente e posteriormente capital gótica da Itália. Consagrado bispo por volta de 580, João II (ou III, dependendo das fontes) de Ravena era tido como um homem de confiança de Gregório. Roma e Ravena disputavam influência política e religiosa na península Itálica desde meados do século $\mathrm{V}$, quando houve a última mudança da capital imperial de Milão para Ravena, antes da capitulação do Império do Ocidente perante os ostrogodos. Durante todo período "gótico". Ravena cresce em importância religiosa e secular, e continua assim durante o período de Gregório. Após a reconquista de 
Justiniano, Ravena se estabelece como centro do poder imperial de Constantinopla no ocidente e se se torna a partir de 582 sede do exarcado.

Desde cedo, foram elaborados artifícios eclesiásticos para que a importância dentro da Igreja correspondesse a sua importância dentro da política secular._Conforme Robert Markus define, "sem Roma, Ravena poderia ser o coração da Itália” (1997, p. 145). Em uma das estratégias para reforçar seu poder politico-simbólico Ravena desenvolveu além do culto de Santo Apolinário (santo local, martirizado no século II), o culto a Santo André. Tal como outras sés da bacia mediterrânica, como Alexandria com São Marcos e Roma com São Pedro, Ravena procurava em Santo André a sua legitimidade eclesiástica, dado que - como irmão de Pedro e apóstolo de Cristo - se Ravena não era assim colocada como superior a Roma, pelo menos estaria no mesmo patamar da sé de Pedro.

Na década de 540, com a conquista de Ravena por Justiniano, a Sé foi elevada para o grau de arquiepiscopado. Conforme o próprio Markus (1997, p. 146) avalia, o título não se mostrava muito claro, e não continha efeitos práticos expressivos, mas servia para diferenciar Ravena frente às outras sés. Após o reinado de Justiniano, Ravena se torna o pivô de uma disputa de hegemonia com Roma na península Itálica, com as disputas dos Três Capítulos. ${ }^{264}$ Efetivamente, em 592, João de Ravena foi um dos primeiros a receber um exemplar da Regula Pastoralis de Gregório acompanhada de uma carta de Gregório assinalada a "João, reverendíssimo e santo irmão, meu colega no episcopado" (Ep. 1.24a). Gregório, político astuto que foi, pregava fervorosamente por uma unidade cristã na liturgia. Com grande maturidade intelectual, e utilizando da grande retórica que lhe era pertinente, estabeleceu na Regra um espírito governativo, atribuindo-Ihe a experiência que teve como aprocrisário e administrador público nas questões pastorais. A advertência de Gregório a João demonstrou isso de maneira sui generis - como uma forma do papado impor seu poder sob os bispos ocidentais cismáticos.

\footnotetext{
${ }^{264}$ A controversa dos Três Capítulos foi uma dentre as várias querelas que ocorreram na Igreja no decorrer dos séculos IV e V na medida em que temos a tentativa de conciliar Igrejas orientais (Síria e Copta) com a ortodoxia.
} 
A Regra trouxe consigo um sentido de ordo (ou "ordem") que foi posteriormente muito cara não somente aos abades, bispos e diáconos (pastores cristãos por excelência), mas também aos reis e imperadores no trato com o "governo das almas". Gregório esclareceu João de Ravena, de forma muito cordata, que o pior pecado que um pastor poderia cometer era o orgulho e que, antes de tudo, o governo das almas era um fardo; porém o que levava a conceber tal obra, não era somente advertir aquele que ambiciona ao serviço pastoral e que não lhe convém, mas também aquele que ocupa um alto grau de governo pastoral - e que o conseguiu de maneira legítima - considere as suas ações para que haja de maneira coerente com o cargo que ocupa. Digno de nota é o fato de que, mesmo falando com um subordinado seu, Gregório revela a sua inexperiência que "não sabendo avaliar-se a si mesmos, aspiram ensinar o que não aprenderam e consideram o fardo deste magistério tanto mais leve quanto mais ignoram a sua grandeza" (Ep. 1.24a).

Isto é, se formos partir da análise marxista do período, nós vamos nos deparar com um momento chave me que a Igreja passou a ser uma superestrutura; isto é, a Igreja não apenas não apenas vai elaborar e explorar uma visão de mundo, mas também gere os meios de produção. Deus, os anjos, e os santos, povoaram as mentalidades dos contemporâneos como se fosse uma estrutura análoga a da terra. Com a dissolução do Senado nas Guerras Góticas e com a debandada dos aristocratas da península Itálica como não há, em nenhum período da história, vácuo de poder -, o poder político caiu no colo do papado ao ponto de que Roma teria uma profunda crise no abastecimento se não fosse as terras da Igreja providenciando os mantimentos para a população. Pois além de suprir as necessidades básicas da população, e em um cenário de contínua guerra, peste e fome, a Igreja também serviu "ânimo de um mundo sem coração, assim como o espírito de estado de coisas embrutecidos" (MARX, 2013). Gregório ainda teria que lidar com as querelas envolvendo o patriarca João VI de Constantinopla que legou para si o título de Patriarca Universal em 595; porém, com as políticas de poder estabelecidas no seu pontificado desde $590 \mathrm{com}$ a Regra pastoral, o bispo de Roma se tronaria "mais universal" que o constantinopolitano. 


\section{Referências}

\section{Documentação}

GREGÓRIO MAGNO. The Letters of Gregory the Great. Tradução, introdução e notas de John R. C. Martyn. Toronto: Pontifical Institute of Medieval Studies, 2004.

GREGÓRIO MAGNO. Regra pastoral. Trad. Sandra Pascoalato. São Paulo: Paulus, 2010.

\section{Bibliografia}

BASTOS, M. J. da M. Escravo, Servo ou Camponês? Relações de Produção e Luta de Classes no Contexto da Transição da Antiguidade à Idade Média. Politeia: História e Sociedade. Vitória da Conquista, v. 10, n. 1, p. 77-105, 2010.

DEMACOPOULOS, G. Gregory the Great: Ascetic, Pastor, and the Frist Man of Rome. Norte Damme: Norte Damme University Press, 2015.

EKONOMOU, A. J. Byzantine Rome and The Greek Popes. Eastern Influences on Rome and the Papacy from Gregory the Great to Zacharias. Plymouth: Lexington Books, 2007.

MARKUS, R. A. Gregory the Great and his World. Cambridge: Cambridge University Press, 1997.

MARX, K. Formações econômicas pré-capitalistas. São Paulo: Paz e Terra, 2011.

MARX, K. Crítica a filosofia do direito de Hegel. São Paulo: Boitempo, 2013.

NEIL, Browen. The Papacy in the Age of Gregory the Great. Em: ; DEL SANTO, Matthew (org.). A Companion to Gregory the Great. Leiden/Boston: Brill, 2013.

PIRENNE, Henry. Maomé e Carlos Magno. O impacto do islã sobre a Civilização europeia. Rio de Janeiro: Contraponto/Editora PUC-Rio, 2010.

RAPP, Claudia. Holy Bishops in Late Antiquity. The Nature of Christian Leadership in an Age of Transition. Los Angeles: California University Press, 2005.

RAPP, Claudia. O legado de Roma. Iluminando a idade das trevas, 400-1000. Campinas: Editora Unicamp, 2019. 